\title{
Minimally Invasive Surgery Versus Open Surgery for the Treatment of Rectal Gastrointestinal Stromal Tumor: A Propensity Score Matching Analysis of Short- and Long-Term Outcomes
}

\section{Yi-Lin Xie}

Department of Endoscopy Center,The First Affiliated Hospital of Xiamen University

\section{Feng-bo Tan}

Gastrointestinal Sugery,Xiangya Hospital Central south univesity

Sheng Liu

Gastrointestinal Surgery,Xiangya Hospital Central South University

Guo-qing Liao

Gastrointestinal Surgery,Xiangya Hospital Central South University

Jing Qi ( $\sim 158102131 @ c s u . e d u . c n)$

Central South University Third Xiangya Hospital https://orcid.org/0000-0001-9558-6742

\section{Research article}

Keywords: Rectal GISTs, minimally invasive surgery, open surgery, propensity score matching

Posted Date: January 9th, 2021

DOI: https://doi.org/10.21203/rs.3.rs-141331/v1

License: (c) (1) This work is licensed under a Creative Commons Attribution 4.0 International License.

Read Full License 


\section{Abstract}

Backgrounds

Rectal GISTs are relatively rare and surgical resection is the potential curative treatment for rectal GISTs. However, limited studies addressing the outcomes of minimally invasive surgery for rectal GIST.

Methods

A total of 32 rectal GIST patients were retrospective from January 2010 to December 2019 at Xiangya hospital Central South University. The demographic and clinicopathologic data were supplemented by our clinic and pathologic system. Selection bias was eliminated using the propensity score matching (PSM) methods

Results

After PSM, 22 patients were finally enrolled in our cohorts, with 11 patients in minimally invasive surgery (MIS) group and 11 patients in open surgery(OPEN) group randomly matched (1:1) by age, gender, body mass index, tumor size, tumor distance above the anal edge. MIS group recived a shorter operating time (108.45 $\pm 31.56 \mathrm{~min}$ vs $136.18 \pm 28.58 \mathrm{~min}, P=0.043)$ and lesser blood less $(67.27 \pm 54.97 \mathrm{~mL}$ vs $194.55 \pm 115.96 \mathrm{~mL}, \mathrm{P}=0.004)$ than OPEN group during the operation. Besides, the MIS group seemed to gain a shorter time to resume borborygmus after operation, flatus passage, resuming oral diet, and hospital stay, but no significantly statistic difference(P凶0.05). Moreover, no differences in rate of 1-year, 3year, and 5-year Progression Free Survival and overall survival was found between two groups.

Conclusion

Compared with open surgery, minimally invasive surgery benefits a shorter operating time and lesser blood less in operation in rectal GISTs. Moreover, similar oncologic outcome was found both in minimally invasive surgery and open surgery in rectal GISTs.

\section{Introduction}

Gastrointestinal stromal tumors (GISTs) are the most common primary mesenchymal tumors in the gastrointestinal tracts, with an annual incidence of 7 to 15 per million population per year [1]. GISTs are believed to have originated from mesenchymal cells (Interstitial cells of Cajal) of the GI tracts. Besides, GISTs can occur throughout the gastrointestinal tract, most frequently in the stomach (51\%) and small intestine (36\%), rarely occur in rectum (5\%)[2]. However, the latter in general have a higher degree of malignancy and poorer prognosis [3].

Surgical resection is the potential curative treatment for the localized GIST. Due to the rare incidence of lymph node metastasis, therefore the routine lymphadenectomy is not indicated in adults. Besides, ESMO guidelines and NCCN guidelines have shown that wide margins of tumor resection have not improved the 
outcomes, so the main recommended goal of resecting GISTs is to achevie both grossly and macroscopic negative margins $(\mathrm{R} 0)[4,5]$, in addition, tumor rupture should be carefully avoid, which is directlly associated with the prognosis [6].

Recently, minimally invasive surgery have been explored for surgeons in treatment of several gastrointestinal tumors, including the rectal cancer. That proven technique is associated with less invasive trauma, shorter recovery times and length of hospital stays, but with no difference in oncological outcomes and survival $[7,8]$, those studies indicate that minimally invasive surgery is feasible and safe to cure the rectal lesions. However, limited studies addressing the minimally invasive surgery for rectal GIST, and the clinical effeciancy about the minimally invasive surgery versus open surgery is not well established. In this study, we aimed to characterize the short-term and long term oncological outcomes among rectal GIST patients conducting minimally invasive surgery versus open surgery.

\section{Patients And Methods}

\section{Patient selection}

Rectal GIST patients were retrospective from January 2010 to December 2019 at Xiangya hospital Central South University. Patients who were assessed as resectable rectal GISTs by at least two experiment surgeons and underwent surgical resection of a primary rectal GIST were included (Fig. 1), and then patients were divided into two groups: whose who underwent open surgery (OPEN) and those who underwent minimally invasive surgery (MIS)(including transanal resection, transanal minimally invasive surgery, transanal endoscopic microsurgery and laparoscopy). The surgery methods (OPEN or MIS) were determined by at least two experienced surgeons. None of the patients converted from minimally surgery to open surgery.

The exclusion criteria for rectal GIST patients in this study including: (1) patients could not tolerate pneumoperitoneum, (2) patients refused to take laparoscopic surgery, (3) patients had other synchronous or heterochronous malignant neoplasia.

This retrospective study was supported by the Medical Ethical Committee of Xiangya Hospital, Central South University (No. 201909812), and due to the retrospective nature of the study, informed consent was waived.

\section{Data collection}

The demographic and clinicopathologic data were supplemented by our clinic and pathologic system, including age, gender, body mass index (BMI), initial symptoms, distance above anal edge, tumor maximal diameter, mitotic index(number of mitoses per 50 high-powered field [HPF]), margin status (negative [R0], microscopically positive [R1], macroscopically positive [R2]), NIH risk categories, ASA score and Perioperative chemotherapy. Intraoperative and Postoperative details including procedure for the surgery of rectal GIST, multivisceral resection, duration of operation, blood loss, time to resume 
borborygmus, Flatus passage and oral diet, the length of hospital stays and postoperative morbility. Follow-up data were collected by our clinic system and connection to the patients, and the last follow-up was conducted in October 2019 or prior to patient death for any cause.

\section{Propensity Score Matching (PSM)}

For all the patients, six covariates (age, gender, body mass index, clinical symptom, tumor size, tumor distance above the anal edge) that might affected the surgery methods of patients were selected to calculated the propensity score. Then, a subset analysis of open surgery and minimally invasive surgery was conducted to evalutate the short- and long-term outcomes.

\section{statistical analyses}

The counting data are shown as percentages, and measurement data are shown as the mean or median with standard deviation (SD). Patient characteristics between each group were compared by chi-square test and Student's t test or one-way ANOVA was used for comparison between different groups. The progression free survival (PFS) and overall survival(OS)was obtained by the Kaplan-Meier method and differences between Kaplan-Meier curves were investigated by the log-rank test. Statistical analysis was performed using SPSS V26.0 (SPSS Inc. USA). A value of P was considered to be statistically significant below the $5 \%$ level.

\section{Results}

\section{Demographic data and clinicopathologic data}

A total of 32 patients with primary rectal GIST who underwent surgery were eligible during January 2010 to December 2018 in Xiangya hospital Central South University, comprising of 21 (65.6\%) male and 11 (34.4\%) female. The mean age of analytic cohort was $52.94 \pm 9.55$ years (range $27-67$ years). Of all the patients, the mean distance above anal edge was $4.31 \pm 2.86 \mathrm{~cm}$ (range $0.5-15.0 \mathrm{~cm}$ ), besides, most of the rectal GIST occurred within $5 \mathrm{~cm}$ to the anal edge in $26(81.2 \%)$ of the 32 patients. The longest diameter of rectal GIST was $6.62 \pm 4.79 \mathrm{~cm}$ (range $0.8-25.0 \mathrm{~cm}$ ). The most common clinical symptom was change of bowel habits (56.3\%), and gene analysis showed most of analytic cohort had kit 11 mutation (59.3\%) (Table 1). 
Table 1

Characterization of rectal gastrointestinal stromal tomor $(n=32)$

\begin{tabular}{|c|c|c|}
\hline \multicolumn{2}{|l|}{ Quality } & \multirow{2}{*}{$\begin{array}{l}N(\%) \text { or mean } \pm \text { SD } \\
52.94 \pm 9.55(27-67)\end{array}$} \\
\hline Mean Age[years](ra & & \\
\hline \multirow[t]{2}{*}{ Gender } & Male & $21(65.6 \%)$ \\
\hline & Female & $11(34.4 \%)$ \\
\hline \multicolumn{2}{|c|}{ Distance above anal edge [cm] (range) } & $4.31 \pm 2.86(0.5-15.0)$ \\
\hline & $\nabla 5 \mathrm{~cm}$ & $6(18.8 \%)$ \\
\hline & $\leq 5 \mathrm{~cm}$ & $26(81.2 \%)$ \\
\hline \multicolumn{2}{|c|}{ Tumor longest diameter [cm] (range) } & $6.62 \pm 4.79(0.8-25.0)$ \\
\hline \multicolumn{2}{|l|}{$\mathrm{BMI}\left(\mathrm{kg} / \mathrm{m}^{2}\right)$} & $22.16 \pm 2.62$ \\
\hline \multirow[t]{5}{*}{ Clinical symptom } & Perianal discomfort & $3(9.4 \%)$ \\
\hline & Hematochezia & $4(12.5 \%)$ \\
\hline & Ventosity & $3(9.4 \%)$ \\
\hline & Change of bowel habits & $18(56.3 \%)$ \\
\hline & Asymptom & $4(12.5 \%)$ \\
\hline \multirow[t]{4}{*}{ ASA Score } & 1 & $5(15.6 \%)$ \\
\hline & 2 & $20(62.5 \%)$ \\
\hline & 3 & $7(21.9 \%)$ \\
\hline & 4 & $0(0 \%)$ \\
\hline \multirow[t]{4}{*}{ Risk category ${ }^{a}$} & Very low risk & $1(3.1 \%)$ \\
\hline & Low risk & $8(25.0 \%)$ \\
\hline & Intermediate risk & $2(6.3 \%)$ \\
\hline & High risk & $21(65.6 \%)$ \\
\hline \multirow[t]{5}{*}{ Genes mutations } & Kit exon 9 & $5(15.6 \%)$ \\
\hline & Kit exon $11^{\mathrm{b}}$ & 19(59.3\%) \\
\hline & Kit exon 13 & $0(0 \%)$ \\
\hline & Kit exon 17 & $1(3.1 \%)$ \\
\hline & PDGFRA & $0(0 \%)$ \\
\hline
\end{tabular}




\begin{tabular}{|c|c|c|}
\hline \multicolumn{2}{|l|}{ Quality } & \multirow{2}{*}{$\begin{array}{l}\mathbf{N}(\%) \text { or mean } \pm \text { SD } \\
7(21.9 \%)\end{array}$} \\
\hline & None(wild-type) & \\
\hline \multirow[t]{2}{*}{ Perioperative chemotherapy } & Yes & $18(56.3 \%)$ \\
\hline & No & $14(43.7 \%)$ \\
\hline \multirow[t]{9}{*}{ Procedure for rectal GIST } & Open surgery(OPEN) & $17(53.1 \%)$ \\
\hline & Anterior resection & 10 \\
\hline & Abdominoperineal resection & 3 \\
\hline & Palliative resection & 4 \\
\hline & Minimally invasive surgery(MIN) & $15(46.9 \%)$ \\
\hline & TER/TR & 7 \\
\hline & Anterior resection(Laparoscope) & 2 \\
\hline & Abdominoperineal resection(Laparoscope) & 6 \\
\hline & Palliative resection & 0 \\
\hline \multicolumn{3}{|c|}{ 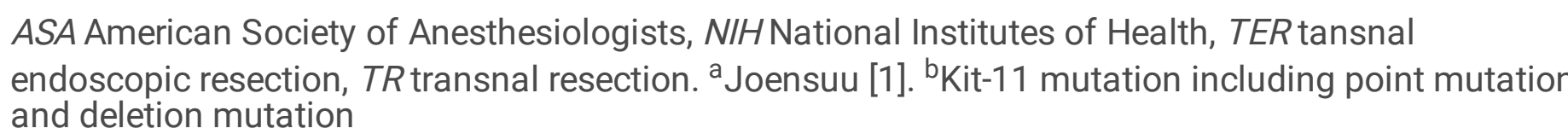 } \\
\hline
\end{tabular}

\section{Intraoperative and Postoperative Outcomes}

Before PSM, 17 patients underwent open surgery (OPEN) and 15 underwent minimally invasive surgery (MIS), and there were significant differences among distance above anal edge, Tumor maximal diameter and $\mathrm{NIH}$ risk category (P囚0.05). After PSM, 11 matched pairs were available for the final analysis, and the above selection bias and confounding factors disappeared $(P \otimes 0.05)$ (Table 2). 
Table 2

Comparison of the open surgery (OPEN) group and minimally invasive surgery (MIS) group in clinicalpathologic characterization before $(n=32)$ and after $(n=22)$ PSM.

\begin{tabular}{|c|c|c|c|c|c|c|}
\hline \multirow[t]{2}{*}{ Characteristics } & \multicolumn{3}{|c|}{ Before matching } & \multicolumn{3}{|c|}{ After matching } \\
\hline & $\begin{array}{l}\text { OPEN } \\
\text { group } \\
(n=17)\end{array}$ & $\begin{array}{l}\text { MIS group } \\
(n=15)\end{array}$ & $\begin{array}{l}P \\
\text { value }\end{array}$ & $\begin{array}{l}\text { OPEN } \\
\text { group } \\
(n=11)\end{array}$ & $\begin{array}{l}\text { MIS group } \\
(n=11)\end{array}$ & $\begin{array}{l}P \\
\text { value }\end{array}$ \\
\hline Age(years) $($ mean $\pm S D)$ & $\begin{array}{l}54.12 \pm \\
9.16\end{array}$ & $\begin{array}{l}51.60 \pm \\
10.12\end{array}$ & 0.466 & $\begin{array}{l}50.64 \pm \\
9.35\end{array}$ & $\begin{array}{l}52.73 \pm \\
11.73\end{array}$ & 0.649 \\
\hline Gender(Male/Female) & $11 / 6$ & $10 / 5$ & 1.000 & $6 / 5$ & $7 / 4$ & 1.000 \\
\hline $\mathrm{BMI}\left(\mathrm{kg} / \mathrm{m}^{2}\right)$ & $\begin{array}{l}22.47 \pm \\
2.84\end{array}$ & $\begin{array}{l}21.81 \pm \\
2.40\end{array}$ & 0.488 & $\begin{array}{l}23.79 \pm \\
2.23\end{array}$ & $\begin{array}{l}21.74 \pm \\
2.62\end{array}$ & 0.062 \\
\hline $\begin{array}{l}\text { Distance above anal edge } \\
\text { (cm) }\end{array}$ & $\begin{array}{l}5.32 \pm \\
3.06\end{array}$ & $3.17 \pm 2.18$ & 0.031 & $\begin{array}{l}5.05 \pm \\
3.44\end{array}$ & $3.41 \pm 2.52$ & 0.217 \\
\hline $\begin{array}{l}\text { Tumor maximal diameter } \\
(\mathrm{cm})\end{array}$ & $\begin{array}{l}8.71 \pm \\
5.21\end{array}$ & $4.27 \pm 2.89$ & 0.007 & $\begin{array}{l}5.96 \pm \\
1.68\end{array}$ & $5.01 \pm 3.08$ & 0.382 \\
\hline Mitotic index & & & 0.088 & & & 0.197 \\
\hline$\leq 5 / 50 \mathrm{HPF}$ & 9 & 11 & & 7 & 8 & \\
\hline 5/50HPF-10/50HPF & 5 & 0 & & 3 & 0 & \\
\hline ه10/50HPF & 3 & 4 & & 1 & 3 & \\
\hline $\mathrm{NIH}$ risk category & & & 0.005 & & & 0.149 \\
\hline Very low-low risk & 1 & 8 & & 1 & 5 & \\
\hline Intermediate-high risk & 16 & 7 & & 10 & 6 & \\
\hline Margin status & & & 0.229 & & & 1.000 \\
\hline $\mathrm{R} 0$ resection & 14 & 15 & & 10 & 11 & \\
\hline $\mathrm{R} 2$ resection & 3 & 0 & & 1 & 0 & \\
\hline $\begin{array}{l}\text { Perioperative } \\
\text { chemotherapy }\end{array}$ & & & 0.153 & & & 0.080 \\
\hline Yes & 5 & 9 & & 2 & 7 & \\
\hline No & 12 & 6 & & 9 & 4 & \\
\hline
\end{tabular}

The operative results were summarized in Table 3. MIS group recived a shorter operating time (108.45 \pm $31.56 \mathrm{~min}$ vs $136.18 \pm 28.58 \mathrm{~min}, P=0.043)$, lesser blood less $(67.27 \pm 54.97 \mathrm{~mL}$ vs $194.55 \pm 115.96 \mathrm{~mL}$, $\mathrm{P}=0.004)$ than OPEN group during the operation. No complication occured in the intraoperative procedure in two groups, and none of the patients in the MIS group needed conversion to open surgery. 
Otherwise, the MIS group seemed to gain a shorter time to resume borborygmus after operation, flatus passage, resuming oral diet, and hospital stay, but no significantly statistic difference(Pख0.05). 1 patients in OPEN group had R2 resection while none in MIS group. The length of postoperative hospital stay for patients who had no postoperative complications was longer in the OPEN group comparing with MIS group $(6.44 \pm 1.33$ vs $4.00 \pm 1.23$ days, $P=0.001)$.

Table 3

Intraoperative and Postoperative outcomes between two groups

\begin{tabular}{|c|c|c|c|}
\hline \multirow[t]{2}{*}{ Characteristics } & OPEN group & MIN group & \multirow[t]{2}{*}{$P$ value } \\
\hline & $(n=14)$ & $(n=13)$ & \\
\hline Operative time, mean $\pm S D$, minutes & $136.18 \pm 28.58$ & $108.45 \pm 31.56$ & 0.043 \\
\hline Blood loss, mean $\pm S D$, mL & $194.55 \pm 115.96$ & $67.27 \pm 54.97$ & 0.004 \\
\hline Time to resume borborygmus, mean $\pm S D$, days & $2.55 \pm 1.04$ & $2.06 \pm 0.83$ & 0.270 \\
\hline Flatus passage, mean \pm SD, days & $3.09 \pm 0.70$ & $2.55 \pm 0.69$ & 0.080 \\
\hline Time to resume oral diet, mean \pm SD,days & $3.00 \pm 1.10$ & $2.36 \pm 0.92$ & 0.156 \\
\hline Length of stay (days)(All) & $7.36 \pm 2.84$ & $8.36 \pm 10.75$ & 0.771 \\
\hline Length of stay (days)(Parts) * & $6.44 \pm 1.33$ & $4.00 \pm 1.23$ & 0.001 \\
\hline Postoperative morbility & $2 / 11$ & 213 & 1.000 \\
\hline Incision infection & 1 & 0 & \\
\hline Postoperative bleeding & 0 & 1 & \\
\hline Anastomotic leakage & 1 & 1 & \\
\hline
\end{tabular}

Overall, the rate of postoperative mobility did not significantly differed between MIS group and OPEN group in rectal GIST patients $(P \otimes 0.05)$. 1 patient got incision infection and another one got anastomotic leakage which finally conducted sigmoidostomy in OPEN group. For the MIS group, 1 patient got postoperative bleeding and cured by local compression for the first one day after operation, one got anastomotic leakage and conducted sigmoidostomy.

\section{Oncologic Outcomes for rectal GISTs}

The median follow-up was 71.55 months for OPEN group and 60.36 months for MIS group. There were no differences in rate of 1-year, 3-year, and 5-year Progression Free Survival and overall survival (Fig. 23 ). No recurrence was observed at the trocar or main surgical wound. During the follow-up period, 6 patients in the OPEN group developed recurrence or metastases (3 liver metastases, 3 local recurrence or pelvic metastases) compared with 5 patients in the MIS group (2 live metastases, 3 local recurrence or pelvic metastases). 


\section{Discussion}

GIST could occur throughout the gastrointestinal tract, most frequently in the stomach and small intestine, and relatively rare in rectum $[9,10]$. Our research found that most of rectal GIST occurred in the lower location of the rectum, with $26(81.2 \%)$ of the 32 patients located occurred within $5 \mathrm{~cm}$ to the anal edge, besides, Shu P, et al also found that $61(85.9 \%)$ of 71 rectal GIST located within $5 \mathrm{~cm}$ to the anal edge[11]. Surgical resection is the standard treatment for resectable rectal GIST, and due to the low location in rectum, surgical methods should be carefully considered because it could lead to an extensive organ resection, which might finally change the living habits permanently.

The first minimally invasive surgery was reported by Philip Mouret of Lyons, France in 1987[12]. Since then, minimally invsive surgery has widely spread. Compared with tranditional open surgery, minimally invasive procedures are generally supposed as a great development of surgical procedures, which could potentially improve the short-term benefits, including alleviate surgical pain, a shorter hospital stay and a quicker recovery from operation. Plenty of studies have demonstrated that minimally invasive surgery get a favouratable effeciency in rectal diseases, including rectal cancer and other benign or malignant rectal lesions $[13,14]$. However, the safety, effeciency, short-term and long-term outcomes of minimally invasive suegry versus open surgery in rectal GISTs still remain to be explore.

The first concern of MIS in rectal GISTs is the safety. Differing from rectal cancer and the exophytic growing feature of rectal GISTs, their large dimensions, low location of rectum and adherent to the surrounding organs densely. Hence, it might be a challenge for surgeons to have a complete recetion with such narrow pelvic space for open surgery [15]. Therefore, minimally invasive surgery might be an alternative surgical methods, because the latter offers a better structural visualization and easily resect the rectal GISTs with minimal trauma. Yang Z et al reported that transnal surgery has a great benefit in rectal GISTs, including short operation time, less blood loss, quick revovery and low complication rate[16]. Several small scale case reports also indicate that transanal endoscopic and laparoscopic excision is safe and could be an alternative treatment of rectal GISTs [17-19]. However, there were no study report the comparision between minimally invasive surgery and open surgery in rectal GISTs. Our research indicated that compared with tranditional open surgery, the minimally invasive surgery was feasible in most of rectal GISTs, none was conversion to open surgery. Additionally, similar postoperative morbidity was found between MIS group and OPEN group. Interestingly, our research found that MIS group recived a shorter operating time and lesser blood less than OPEN group during the operation, indicated that minimally invasive surgery is safety while conducted by experienced surgeons.

The assessment of oncological outcomes is another determining factor for the surgical treatment of rectal GISTs. For other rectal lesions, a systematic review and meta-analysis indicates that laparoscopic surgery for rectal cancer recieves no differences in any oncologic parmeter, disease-free survival and 5year survival compared with tranditional open surgery [20]. However, Martínez-Pérez A et al found laparoscopic mesorectal excision achieved a higher risk of noncomplete excision compared with open mescorecatal excision, but the long-term outcomes still remained to assess [21]. Differing from rectal 
cancer, positive resection margins and tumor rupcture are the most important hazard factors for poorer survival in rectal GISTs $[6,22]$. Hence, surgerons should evaluate and resect tumors carefully without crude procedure. In our center, with careful remove of rectal GISTs both minimally invasive surgery and open surgery by experimental surgeons, none of these patents received R1 section or tumor rupture, otherwise, similar oncologic outcome was obeserved both in MIS group and OPEN group.

Our study have several limitations. First, it is a retrospective study in a experienced center, some confounding variables (such as BMI dietary behavior and others) cannot be compared completely between each group, and due to the low incidence of rectal GISTs, sample size was relative small in this study, which might finally affect the results, further randomized controlled, multiple-center and prospective studies should be performed. Second, we eliminate selection bias and other confounding factors with 5 convariates, there might exist more convariates that could influence the affect the selection of surgery methods.

\section{Conclusion}

Compared with open surgery, minimally invasive surgery benefits a shorter operating time and lesser blood less during operation in rectal GISTs. Moreover, similar oncologic outcome was found between minimally invasive surgery and open surgery in rectal GISTs.

\section{Abbreviations}

GISTs】gastrointestinal stromal tumor

PSMIpropensity score matching

MIS』minimally invasive surgery

OPENDopen surgery

BMIlbody mass index

HPFahigh-powered field

NIHINational Institutes of Health

ASADAmerican Society of Anesthesiologists

SD $\llbracket$ standard deviation

PFSロprogression free survival

OS囚overall survival 


\section{Declarations}

\section{Availability of data and materials}

The datasets used and/or analysed during the current study are available from the corresponding author on reasonable request.

\section{Statements}

\section{Conflict of interest}

The authors declare that they have no conflicts of interest.

\section{Statement of Ethics}

The research was supported by the Medical Ethical Committee of Xiangya Hospital, Central South University (No. 201909812).

\section{Acknowledgements}

Not applicable.

\section{Funding Sources}

We received no funding for the study.

\section{Author Contributions}

Conceived and designed the experiments: Qi J

Analyzed the data: Xie Y, Tan F. Performed the experiments: Xie Y, Tan F, Liu W, Liu S, Liao G.

Wrote the paper: Xie Y,Qi J. All authors read and approved the final manuscript.

\section{References}

[1]. Joensuu H. Risk stratification of patients diagnosed with gastrointestinal stromal tumor. Human Pathology 2008;39:1411-1419.

[2]. Tran T, Davila JA, El-Serag HB. The epidemiology of malignant gastrointestinal stromal tumors: an analysis of 1,458 cases from 1992 to 2000. Am J Gastroenterol 2005;100:162-168.

[3]. Corless CL, Ballman KV, Antonescu CR, Kolesnikova V, Maki RG, Pisters PW, Blackstein ME, et al. Pathologic and molecular features correlate with long-term outcome after adjuvant therapy of resected primary GI stromal tumor: the ACOSOG Z9001 trial. J Clin Oncol 2014;32:1563-1570. 
[4]. Casali PG, Abecassis N, Aro HT, Bauer S, Biagini R, Bielack S, Bonvalot S, et al. Gastrointestinal stromal tumours: ESMO-EURACAN Clinical Practice Guidelines for diagnosis, treatment and follow-up. Ann Oncol 2018;29:iv68-iv78.

[5]. von Mehren M, Randall RL, Benjamin RS, Boles S, Bui MM, Ganjoo KN, George S, et al. Soft Tissue Sarcoma, Version 2.2018, NCCN Clinical Practice Guidelines in Oncology. J Natl Compr Canc Netw 2018;16:536-563.

[6]. Gronchi A, Bonvalot S, Poveda Velasco A, Kotasek D, Rutkowski P, Hohenberger P, Fumagalli E, et al. Quality of Surgery and Outcome in Localized Gastrointestinal Stromal Tumors Treated Within an International Intergroup Randomized Clinical Trial of Adjuvant Imatinib. JAMA Surgery 2020.

[7]. Jayne DG, Guillou PJ, Thorpe H, Quirke P, Copeland J, Smith AM, Heath RM, et al. Randomized trial of laparoscopic-assisted resection of colorectal carcinoma: 3-year results of the UK MRC CLASICC Trial Group. J Clin Oncol 2007;25:3061-3068.

[8]. Park JS, Choi GS, Jun SH, Hasegawa S, Sakai Y. Laparoscopic versus open intersphincteric resection and coloanal anastomosis for low rectal cancer: intermediate-term oncologic outcomes. Ann Surg 2011;254:941-946.

[9]. Qi J, Liu H-L, Ren F, Liu S, Shi W, Liu W-H, Cai G-Q, et al. Preoperative adjuvant therapy for locally advanced and recurrent/metastatic gastrointestinal stromal tumors: a retrospective study. World Journal of Surgical Oncology 2020;18.

[10]. Joensuu H, Vehtari A, Riihimaki J, Nishida T, Steigen SE, Brabec P, Plank L, et al. Risk of recurrence of gastrointestinal stromal tumour after surgery: an analysis of pooled population-based cohorts. Lancet Oncol 2012;13:265-274.

[11]. Shu P, Sun XF, Fang Y, Gao XD, Hou YY, Shen KT, Qin J, et al. Clinical outcomes of different therapeutic modalities for rectal gastrointestinal stromal tumor: Summary of 14-year clinical experience in a single center. Int J Surg 2020;77:1-7.

[12]. Begos DG, Modlin IM. Laparoscopic cholecystectomy: from gimmick to gold standard. J Clin Gastroenterol 1994;19:325-330.

[13]. Lee L, Burke JP, deBeche-Adams T, Nassif G, Martin-Perez B, Monson JRT, Albert MR, et al. Transanal Minimally Invasive Surgery for Local Excision of Benign and Malignant Rectal Neoplasia: Outcomes From 200 Consecutive Cases With Midterm Follow Up. Ann Surg 2018;267:910-916.

[14]. Quaresima S, Balla A, Franceschilli L, La Torre M, lafrate C, Shalaby M, Di Lorenzo N, et al. Transanal Minimally Invasive Surgery for Rectal Lesions. JSLS 2016;20.

[15]. Tielen R, Verhoef C, van Coevorden F, Reyners AK, van der Graaf WT, Bonenkamp JJ, van Etten B, et al. Surgical management of rectal gastrointestinal stromal tumors. J Surg Oncol 2013;107:320-323. 
[16]. Yang Z, Guo W, Huang R, Hu M, Wang H, Wang H. Transanal versus nontransanal surgery for the treatment of primary rectal gastrointestinal stromal tumors: a 10-year experience in a high-volume center. Ann Transl Med 2020;8:201.

[17]. Guerin E, Willemse E, Lefebvre JC, Takieddine M, Dryjski J, Chaikh A, Hayard P, et al. Stromal tumour of the rectum: laparoscopic approach of a rare localization of GIST. Acta Chir Belg 2006;106:605-607.

[18]. Somu K, Dashore AR, Shah AR, Anandh R. Laparoscopic excision of large lower rectal gastrointestinal stromal tumour (GIST): A case report. J Minim Access Surg 2016;12:283-285.

[19]. Eldamshety O, Metwally IH, Ghoneem E, Elkashef WF. Resection of rectal GIST using a novel technique: a report of two cases. Ecancermedicalscience 2017;11:760.

[20]. Pedziwiatr M, Malczak P, Mizera M, Witowski J, Torbicz G, Major P, Pisarska M, et al. There is no difference in outcome between laparoscopic and open surgery for rectal cancer: a systematic review and meta-analysis on short- and long-term oncologic outcomes. Tech Coloproctol 2017;21:595-604.

[21]. Martinez-Perez A, Carra MC, Brunetti F, de'Angelis N. Pathologic Outcomes of Laparoscopic vs Open Mesorectal Excision for Rectal Cancer: A Systematic Review and Meta-analysis. JAMA Surg 2017;152:e165665.

[22]. Liu H, Yan Z, Liao G, Yin H. Treatment strategy of rectal gastrointestinal stromal tumor (GIST). Journal of Surgical Oncology 2014;109:708-713.

\section{Figures}




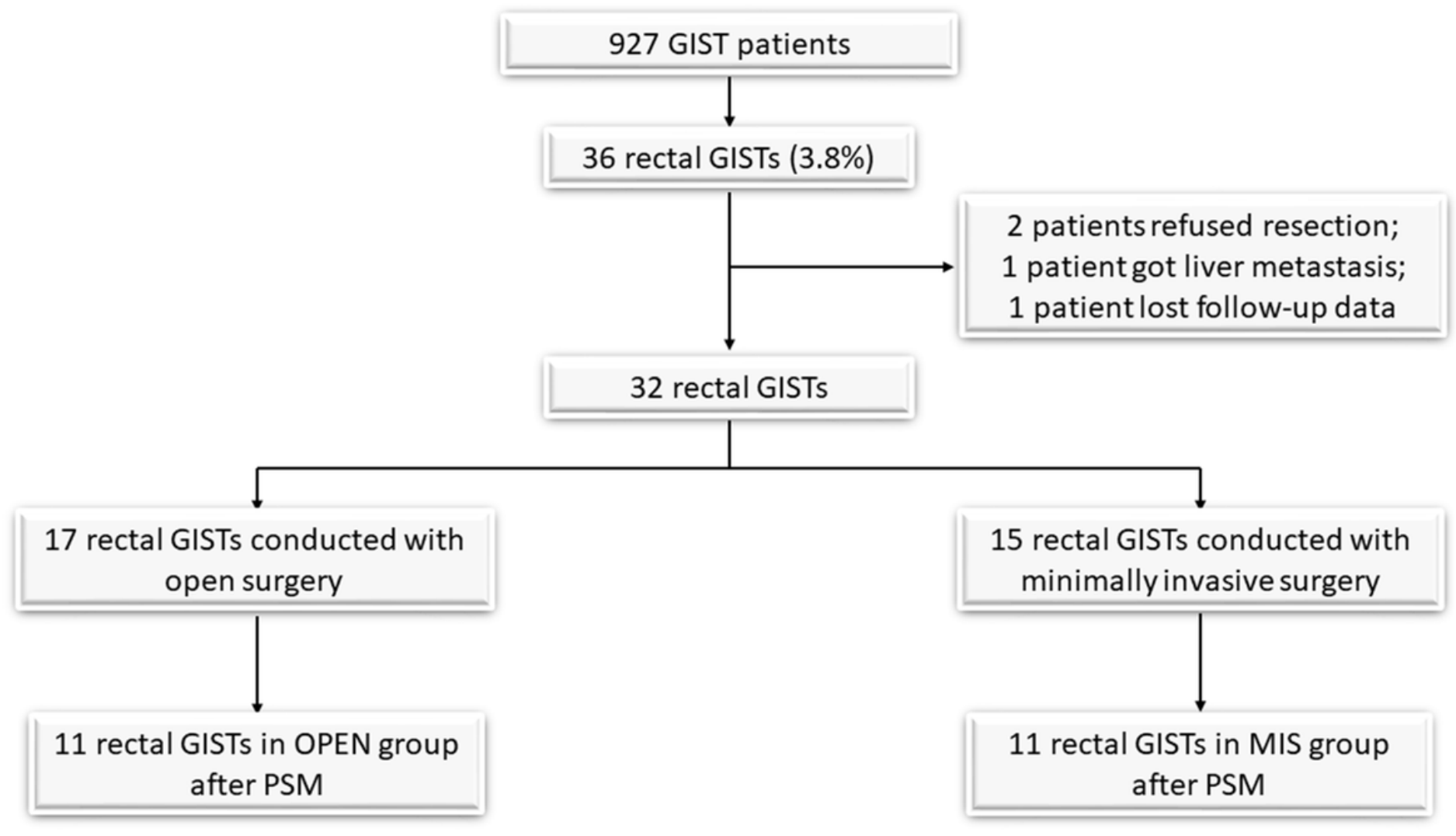

Figure 1

Patients who were assessed as resectable rectal GISTs by at least two experiment surgeons and underwent surgical resection of a primary rectal GIST were included . 


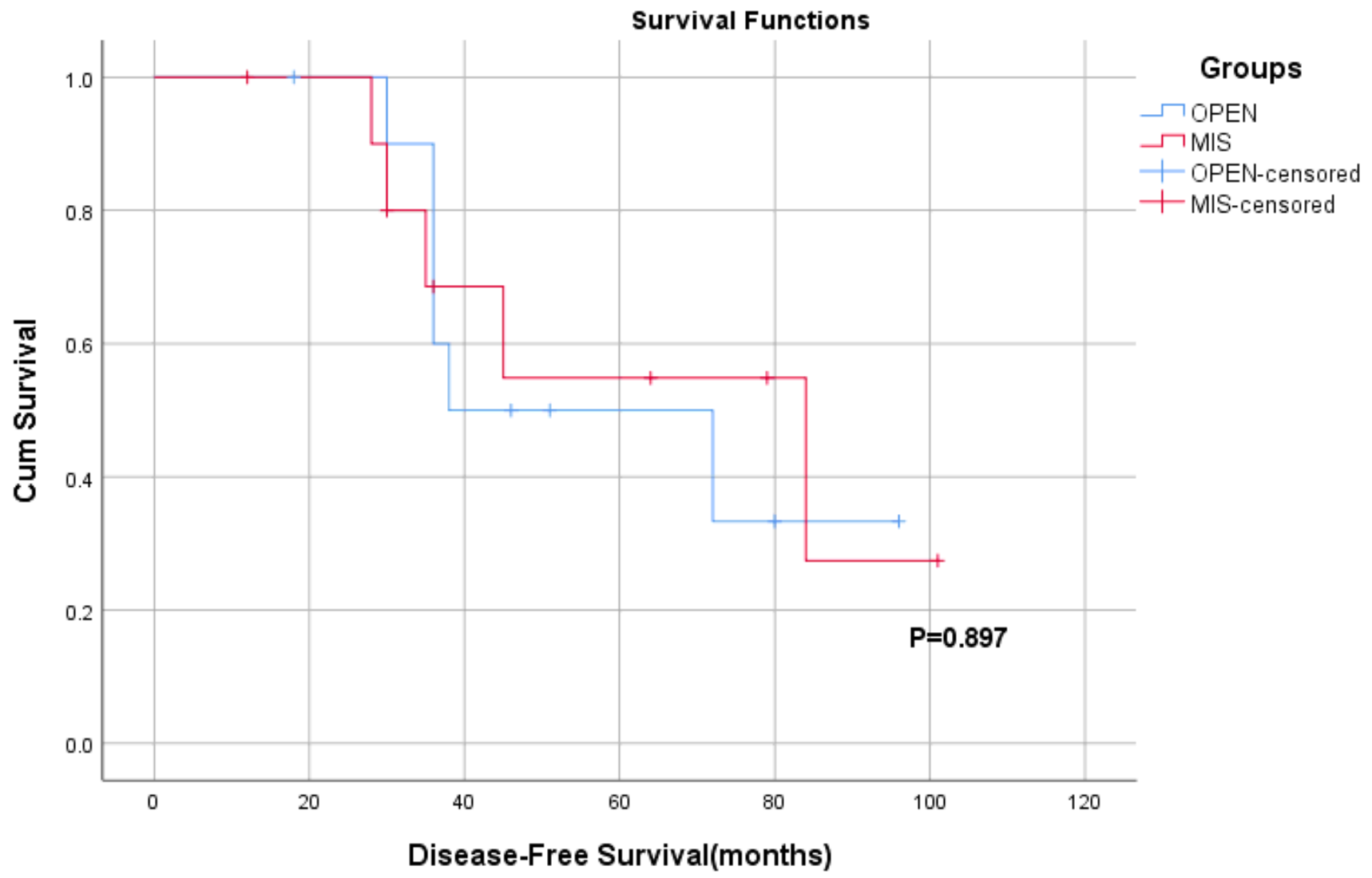

Figure 2

There were no differences in rate of 1-year, 3-year, and 5-year Progression Free Survival and overall survival 


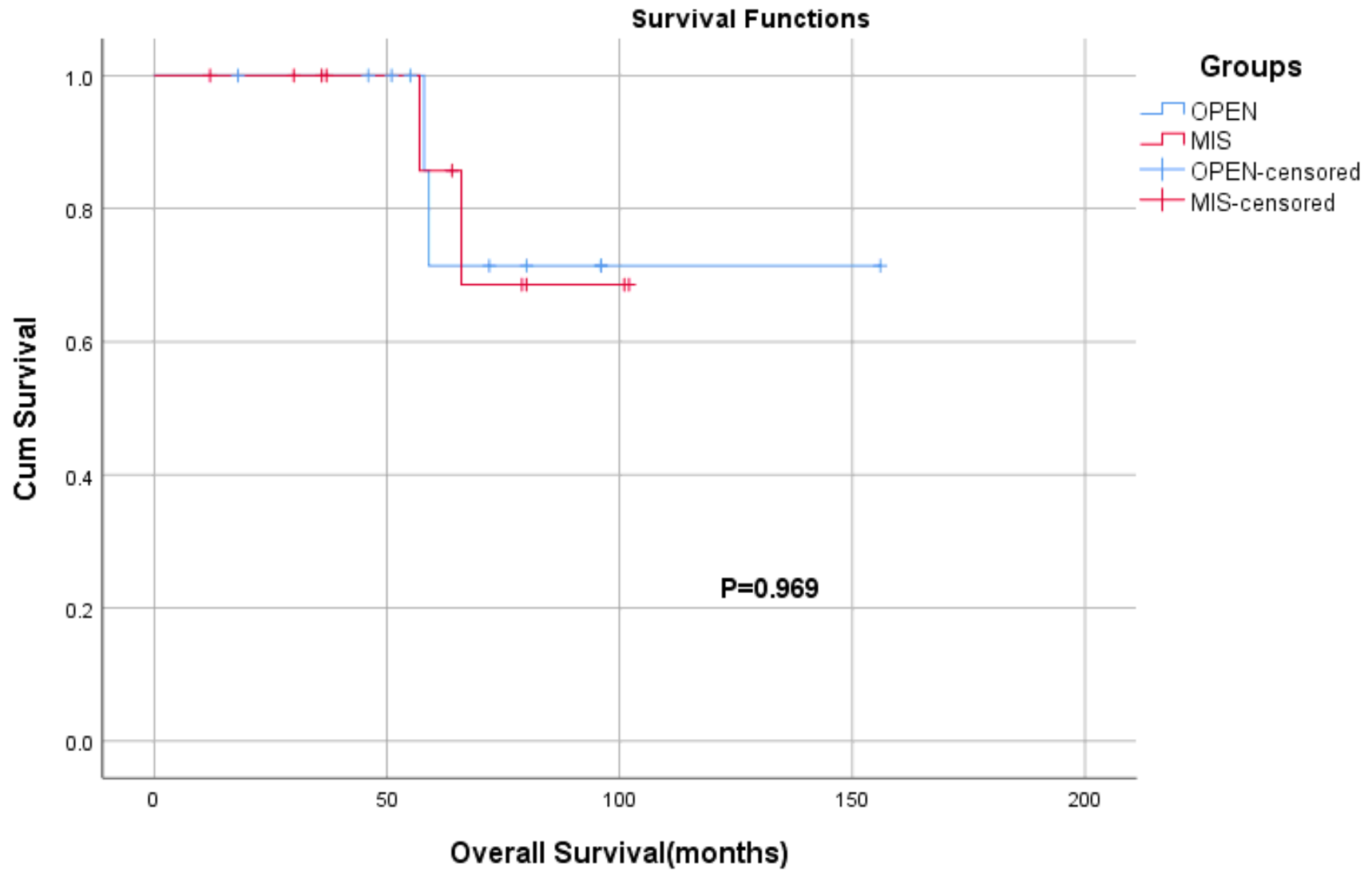

Figure 3

During the follow-up period, 6 patients in the OPEN group developed recurrence or metastases (3 liver metastases, 3 local recurrence or pelvic metastases) compared with 5 patients in the MIS group (2 live metastases, 3 local recurrence or pelvic metastases). 